\title{
Venous Thromboembolism in COVID-19
}

\author{
Sam Schulman ${ }^{1,2}$ Yu Hu ${ }^{3}$ Stavros Konstantinides ${ }^{4,5}$ \\ ${ }^{1}$ Department of Medicine, Thrombosis and Atherosclerosis Research \\ Institute, McMaster University, Hamilton, Ontario, Canada \\ ${ }^{2}$ Department of Obstetrics and Gynecology, I.M. Sechenov First \\ Moscow State Medical University, Moscow, Russia \\ ${ }^{3}$ Institute of Hematology, Union Hospital, Tongji Medical College, \\ Huazhong University of Science and Technology, Wuhan, China \\ ${ }^{4}$ Center for Thrombosis and Hemostasis, University Medical Center \\ Mainz, Mainz, Germany \\ ${ }^{5}$ Department of Cardiology, Democritus University of Thrace, Thrace, \\ Greece
}

Thromb Haemost 2020;120:1642-1653.

Address for correspondence Sam Schulman, MD, PhD, Thrombosis Service, HHS-General Hospital, Hamilton ON L8L 2X2, Canada (e-mail: schulms@mcmaster.ca).

\begin{abstract}
Keywords

- COVID-19

- D-dimer

- risk assessment models

- venous thromboembolism

- prophylaxis

- treatment

The coronavirus disease 2019 (COVID-19) is our latest pandemic, preceded by the H1N1 swine flu in 2009, which lasted approximately 19 months. One of the special characteristics of COVID-19 is the propensity to cause venous thromboembolism (VTE). Thromboinflammation seems to play a prominent role in the pathogenesis. We will here review some mechanisms in the pathogenesis and discuss some hematological biomarkers, and also whether they serve as useful risk factors for VTE. The role of general risk assessment models for medically ill patients specifically in COVID-19 is appraised. The type of prophylaxis and particularly whether standard or augmented doses of chemoprophylaxis should be used is reviewed based on available evidence. We are also comparing recommendations from 10 different guidance or position/consensus statements. Treatment recommendations for patients with COVID-19 and pulmonary embolism are discussed with current general treatment guidelines as reference. Specifics for patients with COVID-19 are pointed out and the potential role of thrombolytic treatment is explored.
\end{abstract}

\section{Introduction}

The coronavirus disease 2019 (COVID-19) is reported to be associated with a high risk of venous thromboembolism (VTE), which occurs in approximately $20 \%$ of COVID-19 patients and tends to be more common in critically ill patients. ${ }^{1-4}$ This incidence is primarily from retrospective studies, and prospective studies with systematic screening for VTE will likely show higher incidences. The prevalence of VTE for COVID-19 patients appeared to be in the higher range compared with patients admitted in intensive care units (ICUs) for other disease conditions. ${ }^{5} \mathrm{~A}$ previous meta-analysis including 1,783 critically infected patients showed an average diagnostic rate of $12.7 \%$ (95\% confidence interval

received

August 5, 2020

accepted after revision

September 4, 2020

[CI]: 8.7-17.5\%) for VTE. ${ }^{6}$ Therefore, it is recommended to assess the risk of VTE in patients with COVID-19, timely identify the risk factors for COVID-19 complicated with VTE, and further reveal its mechanism, so as to facilitate more effective and in-depth anticoagulant prevention and treatment for high-risk patients.

\section{Mechanisms in Pathogenesis of COVID-19}

According to the related studies, COVID-19 appears to center on the interaction between thrombosis and inflammation, causing a hypercoagulable state through mechanisms unique to the pathogen severe acute respiratory syndrome coronavirus 2 (SARS-COV-2). First, SARS-COV-2 enters the alveolar epithelium via the angiotensin

(c) 2020. Thieme. All rights reserved. Georg Thieme Verlag KG,

Rüdigerstraße 14,

70469 Stuttgart, Germany
DOI https://doi.org/ 10.1055/s-0040-1718532. ISSN 0340-6245. 
converting enzyme 2 (ACE2) receptor, leading to the release of excessive inflammatory cytokines (interleukin [IL]-6, tumor necrosis factor, etc.) and chemokines (IL-8, chemokine [C-C motif] ligand [CCL] 2, CCL3, etc.), ${ }^{7,8}$ which further leads to the activation of epithelial cells, monocytes, and neutrophils. Alternatively, endothelial cells can be directly infected through the ACE2 receptor, leading to endothelial activation and dysfunction, thereby triggering a coagulation cascade that generates thrombin and fibrin clot. The activation of platelets and protease-activated receptor signaling pathway during the process further stimulates inflammation, and the interaction between thrombosis and inflammation puts the body in a highly proinflammatory state, leading to local coagulation lesions. ${ }^{9,10}$ As studies have shown, the inflammatory indicator IL-6 is elevated in most COVID-19 patients, and there is a clear correlation between IL- 6 and fibrinogen levels, ${ }^{11}$ which further supports the theory of inflammatory thrombosis.

In addition to triggering dysfunction in pulmonary vessels that leads to inflammatory thrombosis, COVID-19 infection can also lead to an overall hypercoagulable state in the body, leading to macrovascular and microvascular thrombosis. By causing the overactivation of serum complement, the alternative pathway and lectin pathway of the complement are activated and interact with the coagulation pathway. ${ }^{12,13}$ What's more, SARS-COV-2 disrupts renin-angiotensin system via stimulating the ACE receptor, resulting in vasoconstriction and proinflammatory cytokine release, ${ }^{14}$ which further induce and exacerbate cytokine storm and trigger systemic inflammatory response. Studies have reported that a few patients with severe COVID-19 infection expressed antiphospholipid antibodies, for whom there is a possibility of increased risk for thrombosis. ${ }^{15}$ Several studies found that most patients with COVID-19 infection suffered from lymphopenia, ${ }^{2,8,16}$ especially CD4+ cell reduction, and which is more obvious in severe patients. The weakening of the immune system will increase inflammatory response, promote cytokine storm production, worsen the damaged tissues, and increase risks of VTE., 817 Thus, standard anticoagulation may be inadequate in many cases, which means additional or alternative therapies may be needed. ${ }^{18}$ A large number of ongoing studies on the physiopathology of COVID-19-related clotting diseases may provide insights into the mechanisms that guide appropriate intervention strategies.

\section{General Risk Factors for Thrombosis in COVID-19}

According to recent studies, risk factors for VTE in COVID-19 patients include older age, obesity, immobilization, smoking, or comorbidities, such as prior history of VTE, chronic kidney disease, malignant tumor, and heart/respiratory failure. ${ }^{19} \mathrm{~A}$ study has reported that male, white, and African American COVID-19 patients may have more significant hypercoagulability. ${ }^{20}$ In addition, hypoxia, sepsis, preeclampsia, and postpartum infection are also common risk factors for VTE in COVID-19 patients. $^{21,22}$ In other words, all etiologies that lead to hemoconcentration, slow blood rheology, and increased viscosity contribute to the formation of VTE (-Fig. 1).

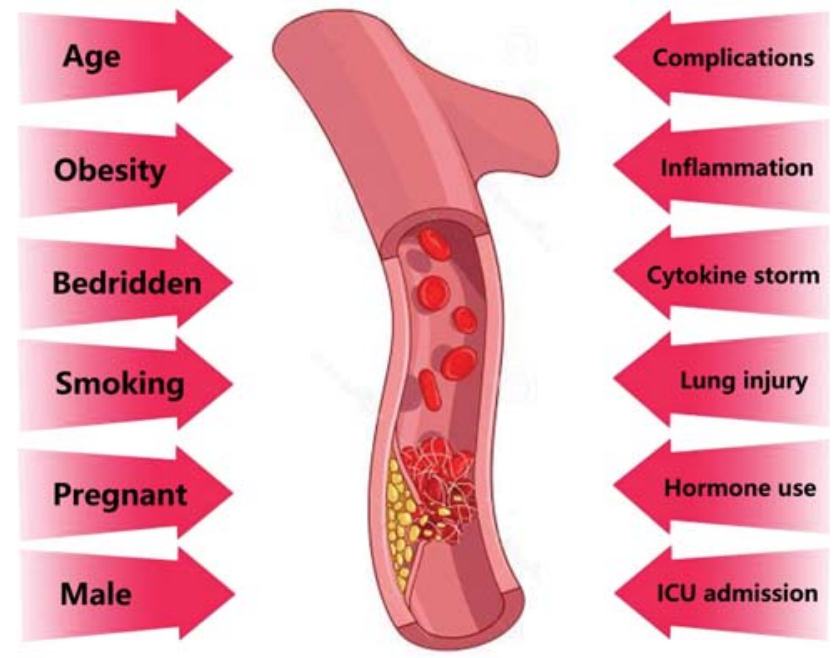

Fig. 1 Risk factors for venous thromboembolism in patients with COVID-19.

Obesity as a risk factor is of special interest and it was recently suggested that adipose tissue may act as a potent inflammatory reservoir for the replication of SARS-COV-2, whereby the inflammatory response also will be more prominent in obese compared with lean patients. ${ }^{23}$

For critically ill patients, a massive release of inflammatory mediators and the administration of hormones (steroids) and immune globulins may further lead to enhanced blood coagulation and increase the incidence of thromboembolic disease. Especially in patients with ICU admission, mechanical ventilation, central venous catheterization, and surgery may cause vascular endothelial injury, and the use of vasopressors, the occurrence of sepsis as well as end-stage renal failure will certainly increase the risk of VTE. ${ }^{5}$ Studies have reported that compared with acute respiratory distress syndrome (ARDS) patients not secondary to COVID-19, ARDS patients secondary to COVID-19 have more thrombosis complications, mainly pulmonary embolism (PE; 11.7 vs. $2.1 \%, p<0.008){ }^{24}$

\section{Biological Markers Associated with VTE}

Abnormal biomarkers can be taken as a reference in the risk assessment. Studies have found that abnormal coagulation parameters in COVID-19 patients are usually associated with poor prognosis, ${ }^{25}$ and D-dimer and fibrinogen degradation products (FDPs) are significantly increased in deaths associated with COVID-19. ${ }^{26}$ The VTE group of COVID-19 patients was different from the non-VTE group in terms of D-dimer level, neutrophil-to-lymphocyte ratio (NLR), lymphocyte count, lactate dehydrogenase level, prothrombin time (PT), etc. $^{3,26,27}$ A significant increase in D-dimer is a sign of activation of coagulation and fibrinolysis, and is a good indicator for identifying high-risk populations with VTE, ${ }^{28}$ which can be used as a highly sensitive test but with low specificity for detection of an active thrombotic process. ${ }^{29} \mathrm{~A}$ study including 81 critically infected patients with COVID-19 concluded that D-dimer levels $>1,500 \mathrm{ng} / \mathrm{mL}$ (normal range: $0.0-0.5 \mathrm{~g} / \mathrm{mL}$ ) had a sensitivity of $85.0 \%$, a specificity of $88.5 \%$, and a negative 
predictive value of $94.7 \%$ for detecting VTE events. ${ }^{30}$ Another prospective study reported similar conclusions. ${ }^{31}$ A metaanalysis of six Chinese studies showed that the mean D-dimer level was $0.44 \mu \mathrm{g} / \mathrm{mL}$ higher (95\% CI: $0.23-0.66$ ) in patients with severe versus nonsevere disease, and $5.91 \mu \mathrm{g} / \mathrm{mL}$ higher in nonsurvivors than in survivors. ${ }^{32}$ However, it should be noted that D-dimer can also be elevated in other conditions, such as pregnancy, postoperatively, malignancy, and sepsis, which needs to be in accordance with the actual situation. The increase of NLR is associated with severe COVID-19 infection. ${ }^{33} \mathrm{~A}$ study reported that the increase of NLR was associated with the formation of VTE, with an average NLR of 9.5 (5.9-13) in 33 patients who developed VTE and 5 (3.5-7.9) in 165 patients without VTE. ${ }^{34}$ A reduced lymphocyte count is common in patients with COVID-19, ${ }^{35}$ which increases the risk of thrombosis, that means elderly patients with underlying diseases are more prone to immune dysfunction due to weakened immunity and so have a higher risk of VTE. In addition, platelet count, PT, activated partial thromboplastin time (aPTT), antithrombin, fibrinogen, FDP, and other related coagulation parameters can provide a reference for thrombosis tendency. ${ }^{36}$ For example, several studies have found that prolonged PT in COVID-19 patients may be related to the severity of the disease and mortality. ${ }^{2,26,37}$ In the abovementioned meta-analysis of Chinese studies, the mean PT was marginally, albeit significantly, longer in severe versus nonsevere cases (mean difference: 0.65 second; $95 \%$ CI: 0.36 0.95 second) and in nonsurvivors versus survivors (mean difference: 1.23 seconds; $95 \%$ CI: $0.60-1.85$ seconds). ${ }^{32}$ Prolonged aPTT and increased FDP are also very common in COVID-19 patients. ${ }^{25}$ However, these indicators should be considered on the basis of actual situation, and their independent indicator role needs to be further confirmed. ${ }^{38}$ Point-ofcare analysis using viscoelastic methods (thromboelastography or rotational thromboelastometry) has been suggested as a rapidly available indicator of a hypercoagulable and/or hyperfibrinolytic state, especially in the ICU setting. ${ }^{39-41}$ The clot formation time and the maximum clot firmness appeared to be particularly useful parameters and probably associated with elevated fibrinogen levels and in turn possibly with deposits of microthrombi in lung vessels. ${ }^{40,41}$

It should be noted that the biological indicators can indicate thrombosis, but cannot predict hypercoagulability. Ultrasound imaging can be used for monitoring and screening in combination with clinical signs and biological indicators of thrombosis, so as to enable early preventive anticoagulant therapy. ${ }^{19,42}$ Given the high incidence of VTE in COVID-19 patients, the study and analysis of the mechanism and etiology of COVID-19 are of great significance for prevention and treatment.

\section{Prophylaxis against Venous Thromboembolism in COVID-19}

High Incidence of Venous Thromboembolism

Early reports from Wuhan, China, ${ }^{27}$ the Netherlands, ${ }^{43}$ France, ${ }^{44}$ and Italy ${ }^{45}$ provided alarming information on a high incidence of VTE in hospitalized patients with
COVID-19. In a systematic review of the literature with 20 studies identified, Di Minno et al noticed a large variability in recorded incidence of VTE-from 3.3 to $100 \%{ }^{46}$ The highest incidence ( $100 \%$ had PE) was seen in an autopsy study, ${ }^{47}$ but in another autopsy study it was $58 \%{ }^{48}$ In nine nonautopsy studies where all patients had been examined with ultrasonography of the leg veins or with computed tomography of pulmonary arteries, the incidence ranged from 15 to $85 \%$ (-Fig. 2). In 10 studies where all patients received deep vein thrombosis (DVT) prophylaxis, the incidence ranged from 8 to 69\%. In 11 studies where all patients were in a critical care unit, the incidence ranged from 8 to $85 \%$.

A scoping review of the literature reported that among 11 eligible studies approximately $20 \%$ of a total of 1,765 patients were diagnosed with VTE, although the cumulative incidence during hospitalization reached $49 \%{ }^{1}$ Furthermore, $3 \%$ of patients in this review had an ischemic stroke. Systematic screening for DVT or PE was only performed in three of the 11 studies, so the true incidence might be higher. Nevertheless, the incidence of VTE is unusually high in most of these studies. In three Dutch hospitals, the incidence of VTE for all hospitalized patients with COVID-19 $(n=579)$, despite universal prophylaxis, was $18.7 \%$ (95\% CI: $14.0-23.4$ ) compared with $1.04 \%$ (95\% CI: $0.92-1.16$ ) in 27,980 patients hospitalized for influenza during 2013 to $2018 .^{49}$

\section{Application of Risk Assessment Models}

In - Table 1, four commonly used risk assessment models are shown with the components that would apply for most of the patients admitted with COVID-19 pneumonia. In two of the four models (Geneva and Padua), ${ }^{50,51}$ the patients would automatically qualify for VTE prophylaxis by quickly adding up to a high risk score. In the IMPROVEDD model, only those admitted to a critical care unit would automatically achieve the high risk score. ${ }^{52}$ However, many of the patients will have additional risk factors, rendering them even higher scores, such as age $>60$ years (Geneva, IMPROVE, and IMPROVEDD) $50,52,53$ or body mass index (BMI) $>30 \mathrm{~kg} / \mathrm{m}^{2}$ (Geneva and Padua) ${ }^{50,51}$ Interestingly, in a comparison of the Geneva, Padua, and IMPROVE models, the former two had similar discrimination, whereas with the IMPROVE model a higher proportion of patients were classified as having low risk for VTE. ${ }^{54}$ The authors proposed that the threshold for low risk should be lowered to $<2$, but alternatively the IMPROVEDD model that adds a twofold elevation of D-dimer can be used. ${ }^{52} \mathrm{~A}$ recent consensus statement published in this journal recommended using the Padua or IMPROVE model to assess risk of VTE in patients with mild or moderate COVID-19. ${ }^{19}$ The vast majority of patients admitted to the hospital with this infection are now quite severely ill, due to the lack of capacity. Thus, it can be concluded that all patients admitted with COVID-19 qualify for VTE prophylaxis based on this assessment of risk.

What Type of Prophylaxis Should Be Used?

The vast majority of studies published on prophylaxis against VTE in COVID-19 have used low-molecular-weight heparin (LMWH). Compared with unfractionated heparin (UFH), it 


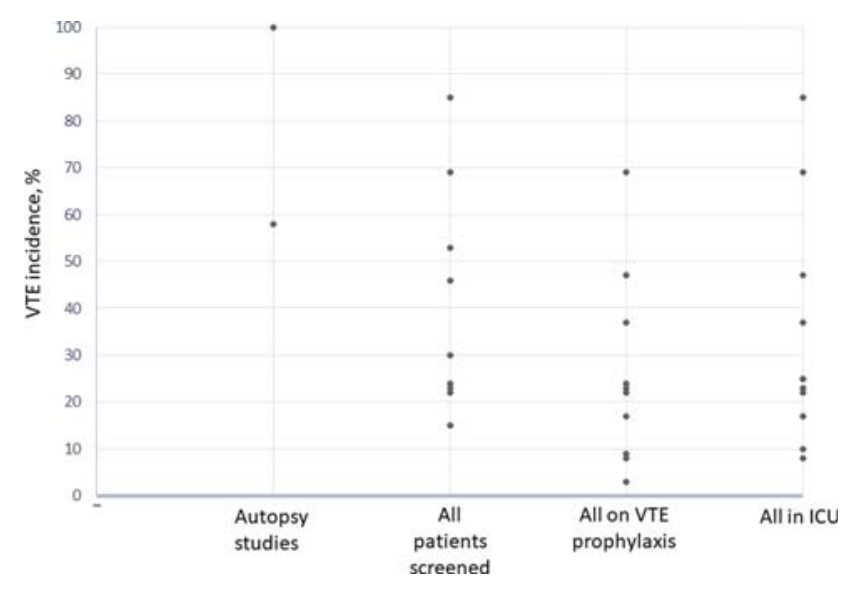

Fig. 2 Reported incidence of venous thromboembolism in hospitalized patients with COVID-19 according to different selection criteria. Data are from 20 studies included in a meta-analysis. ${ }^{46}$ Each dot represents the mean incidence in one study.

has the advantages of once-daily injection with a reduced contamination risk for the staff, more predictable pharmacokinetics with less binding to plasma proteins, particularly to acute-phase reactants, and a lower risk for heparininduced thrombocytopenia. Compared with oral antithrombotic agents, LMWH can be administered to patients who are unable to swallow or are vomiting. Some drugs that are used as antiviral agents (lopinavir and ritonavir) are likely to increase the levels of the nonvitamin $\mathrm{K}$ antagonist oral anticoagulants (NOACs) via inhibition of P-glycoprotein (P-gp) or of the microsomal enzyme CYP 3A4, and the same pertains to azithromycin via P-gp inhibition. ${ }^{55,56}$ These drugs do not interact with LMWH. Furthermore, heparins have an antiinflammatory effect, which might be advantageous for patients with profound inflammatory response reactions.

In an early report from Wuhan, analyzing 449 consecutive patients that had been treated from January 1 to February 13, 2020, 99 patients had been treated for at least 7 days with heparin, mainly with prophylactic-dose $\mathrm{LMWH}^{57}$ Whereas there was no difference in overall 28-day mortality, there was a reduction in mortality for patients with $\mathrm{D}$-dimer above sixfold the upper limit of normal (i.e., above $3.0 \mu \mathrm{g} / \mathrm{mL}$ ) (32.8 vs. $52.4 \%, p=0.017)$. The same effect was seen when selecting patients with sepsis-induced coagulopathy score of $\geq 4$ (40.0 vs. $64.2 \%, p=0.029$ ). There could, however, have been a con- founding effect by other treatments given to the patients who received $\mathrm{LMWH}$.

A subsequent study from New York did not demonstrate a reduced mortality while in hospital for those receiving therapeutic anticoagulation versus those who were not anticoagulated (22.5 vs. $22.8 \%){ }^{58}$ In a subgroup analysis of 395 patients requiring mechanical ventilation, the mortality was, however, reduced for those on therapeutic anticoagulation (29.1 vs. 62.7\%). After adjusting for age, sex, ethnicity, BMI, atrial fibrillation, hypertension, type 2 diabetes, heart failure, use of anticoagulation prior to admission, and date of admission, the proportional hazards model resulted in a hazard ratio (HR) for death of 0.86 per day (95\% CI: $0.82-$ 0.89 ) with therapeutic anticoagulation. Adjustments were not made for antiviral therapies. It is not clear what anticoagulants were used in the therapeutic group and what prophylactic dose-if any-was given to the comparator group.

Another study from the New York City health system during a partially different time period and with different authors analyzed the outcomes in 3,772 hospitalized and ambulatory-managed patients according to whether they were on therapeutic anticoagulation, antiplatelet agents, or nothing (for unrelated reasons) at the time of diagnosis of COVID-19. 59 The crude incidence of overt thrombosis was $1.2 \%$ for those on anticoagulation, $2.1 \%$ for those on antiplatelet agents, and $1.0 \%$ for those on nothing. After propensity matching with adjustments for age, sex, race, Charlson Comorbidity Index, and obesity, when comparing those on anticoagulation with those without any antithrombotic agent at diagnosis, the HR for all-cause mortality was 1.03 (95\% CI: $0.72-1.47)$. For need for mechanical ventilation or admission to the hospital, the corresponding results were HR: 1.24 (95\% CI: 0.81-1.90) and HR: 0.99 (95\% CI: 0.76$1.30)$, respectively.

It thus appears from the larger observational studies that no clear benefit can be derived from therapeutic anticoagulation.

\section{What Dose of LMWH Should Be Used?}

A few published observational studies have presented data on outcomes according to dose of LMWH given. The data are summarized in - Table 2 . A small cohort of patients treated in critical care units at two French hospitals demonstrated a reduced risk for VTE without any difference in mortality with

Table 1 Risk assessment models for venous thromboembolism applied to any patient with COVID-19

\begin{tabular}{|l|l|l|l|}
\hline Geneva $^{50}$ & Padua $^{51}$ & IMPROVE $^{53}$ & IMPROVEDD $^{52}$ \\
\hline Hypercoagulable state $=2$ & Reduced mobility $(3 \mathrm{~d})=3$ & Immobilization $>1 \mathrm{~d}=1$ & Immobilization $>1 \mathrm{~d}=1$ \\
\hline Respiratory failure $=2$ & Heart/respiratory failure $=1$ & Stay in ICU or CCU $=1$ & Stay in ICU or CCU $=1$ \\
\hline Acute infection $=2$ & $\begin{array}{l}\text { Acute infection or rheumatologic } \\
\text { disorder }=1\end{array}$ & & D-dimer $>2 \times$ ULN \\
\hline Immobilization $(<30 \mathrm{~min} / \mathrm{d})=1$ & & & \\
\hline $\boldsymbol{\Sigma}=\mathbf{7}$ & $\mathbf{\Sigma}=\mathbf{5}$ & $\boldsymbol{\Sigma}=\mathbf{2}$ & $\mathbf{\Sigma}=\mathbf{2}$ DD \\
\hline High risk $(\geq 3)$ & High risk $(\geq \mathbf{4})$ & Low risk $(\mathbf{0}-\mathbf{2})$ & High risk \\
\hline
\end{tabular}

Abbreviations: CCU, coronary care unit; ICU, intensive care unit; ULN, upper limit of normal. 
Table 2 Effect of prophylactic versus therapeutic-dose low-molecular-weight heparin on COVID-19 outcomes

\begin{tabular}{|c|c|c|c|c|c|c|c|}
\hline Authors & Setting & $\begin{array}{l}\text { Therapeutic } \\
\text { dose, } \\
\text { N; VTE, } n(\%)\end{array}$ & $\begin{array}{l}\text { Prophylactic } \\
\text { dose, } N \text {; } \\
\text { VTE, } n(\%)\end{array}$ & $p$-Value & $\begin{array}{l}\text { Therapeutic } \\
\text { dose, } N \text {; } \\
\text { death, } n(\%)\end{array}$ & $\begin{array}{l}\text { Prophylactic } \\
\text { dose, } N \text {; } \\
\text { death, } n(\%)\end{array}$ & $p$-Value \\
\hline $\begin{array}{l}\text { Llitjos } \\
\text { et } \mathrm{al}^{44}\end{array}$ & ICU, 2 centers & $18 ; 10(56)$ & $8 ; 8(100)$ & $0.03^{\mathrm{a}}$ & $18 ; 2(11)$ & $8 ; 1(12)$ & n.s. \\
\hline Klok et al ${ }^{60}$ & ICU, 3 centers & $17 ; 3(18)$ & $167 ; 65$ (41) & $0.11^{\mathrm{a}}$ & \multicolumn{2}{|c|}{$\begin{array}{l}\text { Long-term therapeutic versus } \\
\text { prophylactic: HR: } 0.79(95 \% \mathrm{Cl} \text { : } \\
0.35-1.8)\end{array}$} & n.s. \\
\hline $\begin{array}{l}\text { Pesavento } \\
\text { et al }{ }^{61}\end{array}$ & $\begin{array}{l}\text { Medical ward, } \\
2 \text { centers }\end{array}$ & $240 ; 6(2.5)^{b}$ & $84 ; 3$ (3.6) & n.s. & $240 ; 27(11)$ & $84 ; 14(17)$ & n.s. \\
\hline $\begin{array}{l}\text { Al-Samkari } \\
\text { et al }{ }^{62}\end{array}$ & $\begin{array}{l}\text { ICU, } 67 \\
\text { centers }\end{array}$ & Not reported & Not reported & & \multicolumn{2}{|c|}{ HR: $1.12(95 \% \mathrm{Cl}: 0.92-1.35)^{c}$} & n.s. \\
\hline
\end{tabular}

Abbreviations: $\mathrm{Cl}$, confidence interval; HR, hazard ratio; ICU, intensive care unit; n.s., not significant; VTE, venous thromboembolism.

aFisher's exact test.

batients in this group received either intermediate (8\%) or therapeutic (92\%) doses.

'Patients receiving therapeutic anticoagulation first 2 days in ICU versus patients who did not.

therapeutic versus prophylactic dose, but no adjustments were made for potentially confounding factors. ${ }^{44}$

In the updated analyses by Klok et al of 184 patients treated in the ICU of three Dutch hospitals, a competing risk model with adjustment for risk of death was used to estimate the risk of the composite outcome of symptomatic PE, DVT, ischemic stroke, myocardial infarction, and systemic arterial embolism. ${ }^{60}$ For the 17 patients already on long-term therapeutic anticoagulation before admission versus the remaining 160 patients who received prophylactic doses, the HR for the composite outcome was 0.29 (95\% CI: 0.091-0.92). Allcause mortality was, however, not reduced (-Table 2 ).

In an Italian retrospective cohort study of 324 consecutive patients admitted to two medical wards, the main objective was to analyze the risk of bleeding with increased intensity of anticoagulant prophylaxis. ${ }^{61}$ of the 324 patients, 240 received standard prophylaxis and 84 were managed with intermediate or therapeutic doses. There was a statistically significant increase in the latter group for the composite of major and clinically relevant nonmajor bleeding (HR: 3.89; 95\% CI: 1.90-7.97), without any benefits regarding VTE or survival (-Table 2). Adjustments had been made for age, sex, Padua prediction score, renal function, COVID phenotype, concomitant antiplatelet therapy, antibiotics, and proton pump inhibitors.

A large cohort of 3,239 patients at 67 centers in the United States, with critical COVID-19 illness and admission to ICU, has recently been analyzed regarding anticoagulant treatment and thrombosis, bleeding, and death. ${ }^{62}$ The results were presented at the International Society on Thrombosis and Haemostasis 2020 Congress in a latebreaking oral session. Only the results regarding survival were shown and included in the abstract (-Table 2 ). The authors modeled the analysis to imitate a randomized trial between prophylactic and therapeutic doses of anticoagulation started within the first 2 days in the ICU. Adjustments were made for age, sex, BMI, D-dimer level (all four being independent predictors for VTE), and other nonspecified confounders. It is possible that many in the prophylacticdose group had the treatment escalated on day 3 or 4 in the ICU, which in that case could have diluted any differences in outcome.

Colleagues from Milan, Italy, recently discussed the relative rarity of DVT as compared with the frequently found filling defects in pulmonary vessels. ${ }^{63}$ The authors speculate that a prophylactic dose of LMWH protects the patients against DVT but neither this nor a therapeutic dose might be effective in preventing pulmonary thrombi caused by severe inflammation and vascular damage. On the other hand, the occurrence of multisite thrombi simultaneously and without relation to indwelling catheters is frightening and may entice many clinicians to use therapeutic regimens for prophylaxis.

In conclusion, these data do not support the use of higher doses of anticoagulant prophylaxis than those routinely used for other medically ill patients. Randomized trials will be necessary to provide evidence of high quality regarding the best prophylactic regimen and, indeed, more than a dozen such studies are currently recruiting patients.

\section{What Do the Guidance or Position Papers Say Regarding VTE Prophylaxis?}

In the absence of any results from randomized trials and mainly data from small observational studies, it is obvious that formal clinical practice guidelines have not been formulated yet. All guidance documents or position papers agree that essentially every patient admitted with COVID-19 should receive prophylaxis with preferably LMWH (-Table 3). ${ }^{64-72}$ A few documents state that in the case of high bleeding risk chemoprophylaxis should not be used and/or that mechanical prophylaxis instead is recommended. Several documents suggest that intermediate doses be considered for patients with additional risk factors and most do not suggest therapeutic anticoagulation for any patients unless they have been diagnosed with VTE. Prophylaxis for patients treated at home is rarely discussed and 
Venous Thromboembolism in COVID-19 Schulman et al. 1647

Table 3 Suggestions or recommendations regarding VTE prophylaxis in various guidance documents or position/consensus statements

\begin{tabular}{|c|c|c|c|c|c|c|}
\hline \multirow{2}{*}{$\begin{array}{l}\text { Society, } \\
\text { authors, and } \\
\text { ref }\end{array}$} & \multirow{2}{*}{$\begin{array}{l}\text { Not admitted } \\
\text { Prophylactic- } \\
\text { dose LMWH }\end{array}$} & \multicolumn{4}{|c|}{ Admitted to hospital } & \multirow{2}{*}{$\begin{array}{l}\text { Post- } \\
\text { discharge }^{\text {a }}\end{array}$} \\
\hline & & $\begin{array}{l}\text { Prophylactic- } \\
\text { dose LMWH }\end{array}$ & $\begin{array}{l}\text { Intermediate- } \\
\text { dose LMWH }\end{array}$ & $\begin{array}{l}\text { Therapeutic- } \\
\text { dose LMWH }\end{array}$ & $\begin{array}{l}\text { Mechanical } \\
\text { prophylaxis }\end{array}$ & \\
\hline $\begin{array}{l}\text { ISTH, Thachil } \\
\text { et al }\end{array}$ & Not discussed & All patients & - & - & & Not discussed \\
\hline $\begin{array}{l}\text { ISTH, Spyro- } \\
\text { poulos et al }^{65}\end{array}$ & Not discussed & $\begin{array}{l}\text { All patients, } \\
\text { modified for } \\
\text { extreme body } \\
\text { weight, severe } \\
\text { thrombocyto- } \\
\text { penia, or se- } \\
\text { vere renal } \\
\text { failure }\end{array}$ & $\begin{array}{l}\text { May be } \\
\text { considered, } \\
\text { especially for } \\
\text { high-risk } \\
\text { patients }\end{array}$ & - & $\begin{array}{l}\text { Should be } \\
\text { considered on } \\
\text { top of LMWH }\end{array}$ & $\begin{array}{l}\text { All patients } \\
\text { that meet high } \\
\text { risk for VTE } \\
\text { criteria,14-30 } \\
\text { days }\end{array}$ \\
\hline $\begin{array}{l}\text { SFMV, Khider } \\
\text { et al }\end{array}$ & $\begin{array}{l}\text { If VTE risk fac- } \\
\text { tors present: } \\
7-14 \text { days }\end{array}$ & All patients & - & - & - & No \\
\hline $\begin{array}{l}\text { SISET, Marietta } \\
\text { et al }{ }^{67}\end{array}$ & Not discussed & All patients & $\begin{array}{l}\text { Consider on } \\
\text { individual ba- } \\
\text { sis if multiple } \\
\text { VTE risk fac- } \\
\text { tors involved }\end{array}$ & Not supported & $\begin{array}{l}\text { Contraindica- } \\
\text { tion to antico- } \\
\text { agulants }\end{array}$ & $\begin{array}{l}\text { Patients with } \\
\text { persisting VTE } \\
\text { risk factors, } \\
7-14 \text { days }\end{array}$ \\
\hline ASH web site ${ }^{68}$ & Not discussed & $\begin{array}{l}\text { All patients; } \\
\text { LMWH rather } \\
\text { than UFH }\end{array}$ & $\begin{array}{l}\text { For obesity as } \\
\text { per local } \\
\text { protocols }\end{array}$ & $\begin{array}{l}\text { Only in ran- } \\
\text { domized trials }\end{array}$ & - & $\begin{array}{l}\text { Consider as per } \\
\text { individual risk } \\
\text { factors }\end{array}$ \\
\hline $\begin{array}{l}\text { SEDAR-SEMI- } \\
\text { CYUC, Llau } \\
\text { et al }\end{array}$ & Not discussed & All patients & $\begin{array}{l}\text { For mechanical } \\
\text { ventilation, D- } \\
\text { dimer/fibrino- } \\
\text { gen/ferritin } \\
4 \times \text { ULN or } \\
\text { platelet } \\
\text { count }>500- \\
\times 10^{9} / \mathrm{L}\end{array}$ & $\begin{array}{l}\text { Consider if he- } \\
\text { modynamic in- } \\
\text { stability, re- } \\
\text { fractory hyp- } \\
\text { oxemia, or } \\
\text { suspected VTE }\end{array}$ & - & Not discussed \\
\hline $\begin{array}{l}\text { Anticoagula- } \\
\text { tion Forum, } \\
\text { Barnes et al }\end{array}$ & Not discussed & All patients & $\begin{array}{l}\text { Critically ill, } \\
\text { extreme high } \\
\text { weight, third } \\
\text { trimester of } \\
\text { pregnancy }\end{array}$ & - & $\begin{array}{l}\text { Contraindica- } \\
\text { tion to antico- } \\
\text { agulants or } \\
\text { critically ill }\end{array}$ & $\begin{array}{l}\text { Selected cases, } \\
6-14 \text { days }\end{array}$ \\
\hline $\begin{array}{l}\text { Grupo de Tra- } \\
\text { bajo de Trom- } \\
\text { bosis Cardio- } \\
\text { vascular de la } \\
\text { Sociedad Espa- } \\
\text { ñola de Cardi- } \\
\text { ología, Vivas } \\
\text { et al }\end{array}$ & Not discussed & All patients & $\begin{array}{l}2 \text { or more of } \\
\text { (CRP }>15, \text { D- } \\
\text { dimer }>3 \times \\
\text { ULN, IL-6 }>40 \text {, } \\
\text { ferri- } \\
\text { tin }>1,000 \text {, } \\
\text { lympho- } \\
\text { cytes }<0.8 \text { ) } \\
\text { Previous VTE, } \\
\text { ischemic arte- } \\
\text { riopathy, cen- } \\
\text { tral venous } \\
\text { catheter, or D- } \\
\text { dimer }>6 \times \\
\text { ULN }\end{array}$ & $\begin{array}{l}2 \text { or more of } \\
\text { (CRP }>15, \mathrm{D}- \\
\text { dimer }>3 \times \\
\text { ULN, IL-6 }>40 \text {, } \\
\text { ferri- } \\
\text { tin }>1,000 \text {, } \\
\text { lympho- } \\
\text { cytes }<0.8) \\
\text { Previous VTE, } \\
\text { ischemic arte- } \\
\text { riopathy, cen- } \\
\text { tral venous } \\
\text { catheter, or D- } \\
\text { dimer }>6 \times \\
\text { ULN }\end{array}$ & - & Not discussed \\
\hline \multirow{2}{*}{$\begin{array}{l}\text { Swiss consen- } \\
\text { sus statement } \\
\text { by the Working } \\
\text { Party Hemo- } \\
\text { stasis, Casini } \\
\text { et al }\end{array}$} & Not discussed & All patients & - & - & - & Not discussed \\
\hline & & & Not discussed & Not discussed & & \\
\hline
\end{tabular}


Table 3 (Continued)

\begin{tabular}{|c|c|c|c|c|c|c|}
\hline \multirow{2}{*}{$\begin{array}{l}\text { Society, } \\
\text { authors, and } \\
\text { ref }\end{array}$} & \multirow{2}{*}{$\begin{array}{l}\text { Not admitted } \\
\text { Prophylactic- } \\
\text { dose LMWH }\end{array}$} & \multicolumn{4}{|c|}{ Admitted to hospital } & \multirow{2}{*}{$\begin{array}{l}\text { Post- } \\
\text { discharge }^{a}\end{array}$} \\
\hline & & $\begin{array}{l}\text { Prophylactic- } \\
\text { dose LMWH }\end{array}$ & $\begin{array}{l}\text { Intermediate- } \\
\text { dose LMWH }\end{array}$ & $\begin{array}{l}\text { Therapeutic- } \\
\text { dose LMWH }\end{array}$ & $\begin{array}{l}\text { Mechanical } \\
\text { prophylaxis }\end{array}$ & \\
\hline $\begin{array}{l}\text { Thrombosis } \\
\text { and Haemo- } \\
\text { stasis Consen- } \\
\text { sus Statement, } \\
\text { Zhai et al }\end{array}$ & $\begin{array}{l}\text { If high risk for } \\
\text { VTE, by using a } \\
\text { RAM }\end{array}$ & $\begin{array}{l}\text { All patients } \\
\text { unless } \\
\text { contraindi- } \\
\text { cated }\end{array}$ & & & $\begin{array}{l}\text { If high risk of } \\
\text { bleeding }\end{array}$ & $\begin{array}{l}\text { Persistent risk } \\
\text { of VTE, LMWH } \\
\text { preferred }\end{array}$ \\
\hline
\end{tabular}

Abbreviations: ASH, American Society of Hematology; CRP, C-reactive protein; IL-6, interleukin 6; ISTH, International Society on Thrombosis and Haemostasis; LMWH, low-molecular-weight heparin; RAM, risk assessment model; SEDAR-SEMICYUC, Sociedades científicas de AnestesiologíaReanimación y Terapéutica del Dolor and Medicina Intensiva, Crítica y de Unidades Coronarias; SFMV, French Society of Vascular Medicine; SISET, Italian Society on Thrombosis and Haemostasis; UFH, unfractionated heparin; ULN, upper limit of normal; VTE, venous thromboembolism.

${ }^{a}$ The criteria for increased risk of VTE typically quoted are body mass index $>30 \mathrm{~kg} / \mathrm{m}^{2}$, age $>70$ years, active cancer, personal history of VTE, major surgery within the last 3 months, and reduced mobility.

postdischarge prophylaxis is suggested by half of the documents for patients at continued high risk for VTE, typically only for 1 to 2 weeks. The latter issue was addressed in a quality-improvement program in the United Kingdom, where the postdischarge rate of VTE was 4.8 per 1,000 discharges in 1,877 patients with COVID-19 versus 3.1 per 1,000 discharges in 18,519 patients with medical illness in 2019 , corresponding to an odds ratio of 1.6 (95\% CI: 0.77$3.1)^{73}$ The benefit of postdischarge prophylaxis therefore seems doubtful, at least for the majority of patients with COVID-19.

\section{Treatment of Venous Thromboembolism: What Changes in COVID-19 Compared with the Recommendations for the General Population?}

The Choice of the Right Anticoagulant

General recommendations: Anticoagulation treatment is the mainstay of therapy for every patient with acute VTE. Especially in the case of PE, current guidelines emphasize that anticoagulation should be initiated already upon clinical suspicion in patients with high or intermediate clinical (pretest) probability, while awaiting the results of diagnostic imaging tests. ${ }^{74}$ If the parenteral route is preferred for initiation and acute-phase treatment, subcutaneous, weight-adjusted therapeutic-dose LMWH is the first choice, while subcutaneous fondaparinux or intravenous infusion of UFH may be used as an alternative. ${ }^{74,75}$ In most countries, UFH infusion is nowadays only preferred in the case of hemodynamic instability (high-risk PE) and need for emergency reperfusion treatment, or in patients with extreme obesity or severely reduced renal function (creatinine clearance $<30 \mathrm{~mL} / \mathrm{min}$ ). In patients with DVT, and in the vast majority ( $>95 \%$ ) of patients with PE who are hemodynamically stable at presentation, anticoagulation can also be started directly via the oral route, using one of the NOACs: apixaban or rivaroxaban. In any case, i.e., regardless of the decision in favor of, or against a lead-in phase of parenteral treatment, NOACs (apixaban, rivaroxaban, edoxaban, or dabigatran) are preferred over vitamin $\mathrm{K}$ antagonists (VKAs) for chronic oral treatment and secondary prophy- laxis. ${ }^{74,76}$ The strong recommendation in favor of NOACs is in line with the one for stroke prevention in atrial fibrilla$\operatorname{tion}^{77}$ and is based on the solid evidence supporting the efficacy and comparative safety of these drugs during chronic use. Of note, NOACs are either not recommended or formally contraindicated in severe renal impairment, in patients with the antiphospholipid antibody syndrome, and during pregnancy and lactation. The European Heart Rhythm Association regularly updates a practical guide for the use of NOACs in clinical practice, and for the management of emergency situations that may occur during the use of these drugs. ${ }^{78}$

What changes in patients with COVID-19 infection? While the above principles and recommendations on anticoagulation for acute VTE also fully apply to patients with COVID-19, several disease-specific, clinically important issues need to be considered in this setting.

- First, it has been established, based on numerous cohort studies, that both the risk of coagulation abnormalities in the laboratory 35,56 and that of clinically confirmed VTE $^{30,44,45,60,79,80}$ increase with the severity of infection with SARS-CoV-2. In fact, and in contrast to other RNAtype viruses such as Ebola, which predispose to bleeding, acute infection with SARS-CoV-2 mostly results in a prothrombotic state. ${ }^{81}$ It is thus to be expected that many of the patients with COVID-19, who are diagnosed with VTE (particularly acute PE), will have severe infection or be in a critical condition. ${ }^{19}$ In the remaining, "stable" patients, the possibility of rapid cardiorespiratory deterioration and multiple organ failure needs to be taken into account. Because of this, initiation of anticoagulation via the parenteral route, using LMWH (or intravenous UFH in the presence of overt hemodynamic instability) appears preferable for the majority of hospitalized patients; transition to a NOAC can take place in the recovery phase, as soon as the patient's condition is stabilized.

- For patients with COVID-19 receiving intravenous UFH infusion, dose adjustments based on anti-Xa level monitoring may be preferable to aPTT measurements due to 
the heterogeneity in the response of the latter to heparin, which may be expected in this setting. 81,82

- In patients treated with a NOAC, monitoring of renal function is clearly indicated during the acute phase. Besides, one should be aware of possible interactions with experimental treatment for COVID-19. While agents tested early in the course of the epidemic, notably lopinavir/ritonavir and hydroxychloroquine/azithromycin, offered the potential for interactions with NOACs via cytochrome P450 and/or P-gp inhibition, ${ }^{56}$ no significant risks appear to exist in this regard with the agents currently under investigation. Nevertheless, precise knowledge of the patient's disease-specific (standard or experimental) medication is mandatory before deciding in favor of a specific anticoagulant.

- The frequent presence and detection of antiphospholipid antibodies in patients with COVID-19, particularly those who are in critical condition, is an alarming fact, the medical relevance of which remains obscure at this stage. Following an early report on three critically ill patients with anticardiolipin immunoglobulin $\mathrm{A}(\operatorname{Ig} \mathrm{A})$ and anti- $\beta 2$ glyoprotein IgA and IgG, who suffered multiple cerebral infarctions, ${ }^{15}$ a series from China found that antiphospholipid antibodies were common (only) in critical illness related to COVID-19, being positive in 31 out of the 66 patients studied; of the 13 patients in noncritical condition, none tested positive. ${ }^{83}$ In another retrospective series of 25 patients from France, 32\% exhibited single positivity, $52 \%$ double positivity, and $12 \%$ triple positivity. ${ }^{84}$ The development of antiphospholipid antibodies in association with acute or chronic viral disease has been described in the past, ${ }^{85}$ and persistence over time appears to be an important determinant of their association with clinical thrombotic events. Consequently, longitudinal studies are urgently needed to examine the temporal pattern(s) of the kinetics of antiphospholipid antibodies in patients with COVID-19, and to draw conclusions to support anticoagulant treatment decisions. Until such data become available, uncertainty persists whether antiphospholipid testing should routinely be performed before initiating treatment with a NOAC in a patient recovering from COVID-19, in view of the concerns on the efficacy and safety of these drugs in this context. ${ }^{86,87}$ Although no evidence-based recommendations can be made to this date, it seems wise to perform initial and (in the case of positivity) follow-up antiphospholipid antibody testing in patients who were critically ill in the acute phase of the infection, particularly when change of the anticoagulant to a NOAC is envisaged.

- Finally, and as already mentioned above, VKAs are generally no longer the preferred anticoagulant in patients with VTE. In the setting of COVID-19, the need for frequent contacts with health care providers (and other patients) related to anticoagulation monitoring makes these drugs an even less attractive option, with the exception of specific clinical circumstances such as the presence of mechanical prosthetic valves or the antiphospholipid syndrome.

\section{Further Antithrombotic Treatment Options and Integrated Risk-Adjusted Strategies}

General recommendations: Systemic intravenous thrombolysis/fibrinolysis is recommended as first-line reperfusion treatment with acute PE and hemodynamic instability (high-risk PE). In the case of contraindications to thrombolysis, mostly related to a high bleeding risk, or if thrombolytic agents have been administered but failed, emergency surgical pulmonary embolectomy and percutaneous catheterdirected treatment represent rescue options. At the other end of the severity spectrum, patients with low-risk PE should be considered for immediate (or early) discharge and continuation of anticoagulation treatment at home, if proper outpatient care and anticoagulant treatment can be provided. ${ }^{74}$ An integrated risk-adjusted treatment strategy, recently proposed in the updated guidelines of the European Society of Cardiology and the European Respiratory Society, is shown in -Fig. 3.

\section{What Changes in Patients with COVID-19 Infection?}

- The COVID-19 pandemic generated new interest in fibrinolytic agents and their possible merits in treating severe infection with SARS-CoV-2, not only in patients with PE but also in those without confirmed PE. ${ }^{82}$ The rationale lies, at least theoretically, in the massive inflammatory reaction and cytokine storm which characterize the infection and lead to fibrin deposition in the air spaces and lung parenchyma, thus aggravating the course of ARDS. ${ }^{88}$ Targeted use of fibrinolytic agents such as alteplase, preferably in nebulizer form, appears worthy of further investigation; on the other hand, the bleeding risks of systemic fibrinolytic treatment preclude its broader use in the context of COVID-19 beyond the indication of highrisk PE already mentioned above. Furthermore, there is at present no clinical evidence to support early fibrinolytic treatment as a means of preventing transition of acute PE to chronic thromboembolic pulmonary disease. ${ }^{89}$

- Guideline recommendations aim not only at optimizing specific treatment options for individual patients, but also at rationalizing the use of resources of hospitals and national health care systems. This is an important reason why guideline recommendations, such as those briefly outlined above, should be followed during a pandemic, and it definitely also applies to risk-adjusted treatment of VTE during the COVID-19 pandemic. ${ }^{90}$ For patients with high-risk and (in selected cases) intermediate-risk PE, setting up multidisciplinary "PE response teams" helps to streamline treatment decisions, taking into account the availability of expert personnel and technical resources at a given institution and a given moment in time, in dependence of the burden imposed by a COVID-19 outbreak. For patients with low-risk PE, immediate or early discharge should strongly be encouraged to protect the patients themselves from hospital-acquired superinfections as well as health care workers and other patents from becoming infected, and to increase the hospital's capacity in terms of bed availability for (more) seriously ill patients. 


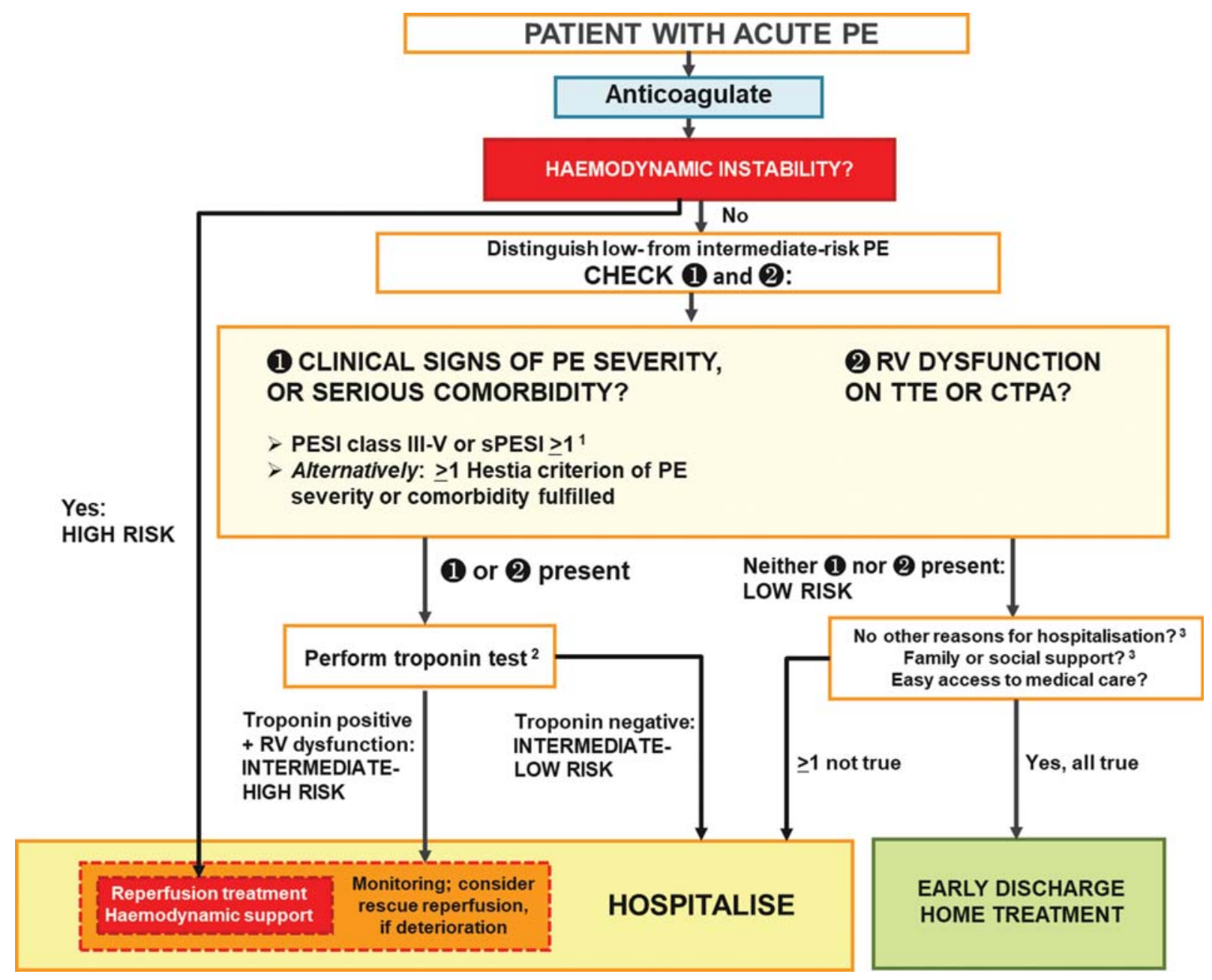

Fig. 3 Proposed risk-adjusted management of patients with acute pulmonary embolism, including those infected with SARS-CoV-2. CTPA, computed tomography pulmonary angiography/angiogram; PE, pulmonary embolism; PESI, Pulmonary Embolism Severity Index; RV, right ventricular; sPESI, simplified Pulmonary Embolism Severity Index; TTE, transthoracic echocardiogram. ${ }^{1}$ Cancer, heart failure, and chronic lung disease are the comorbidities included in the PESI and sPESI. ${ }^{2}$ A cardiac troponin test may already have been performed during initial diagnostic work-up (e.g., in the chest pain unit). Troponin is proposed as the preferred biomarker, because it is the only one to have been used in an interventional trial. ${ }^{91}{ }^{3}$ It is also included in the Hestia criteria. ${ }^{92}$ (Adapted from Konstantinides et $\mathrm{al}^{74}$ with permission from Oxford University Press.)

\section{Conclusion}

The SARS-COV-2, via its specific pathogenic mechanisms, promotes a strong inflammatory response with release of cytokines, chemokines, and cell activation. Through interactions between inflammation, complement activation, and coagulation, a hypercoagulable state is generated. In addition to the well-described increase in D-dimer as a potential biomarker for VTE, the NLR has also shown association. Other coagulation tests might add information but have to be understood in the context of the severe illness.

The reported incidence of VTE in patients with COVID varies widely between studies, even when filtered for specific study characteristics. Risk assessment models may be used to support decisions on prophylaxis, but for the generally severely ill patients with COVID-19 who are admitted to the hospital, almost all patients should receive chemoprophylaxis or, in the case of high risk for bleeding, mechanical prophylaxis. The most commonly recommended and used prophylaxis agent is LMWH. For admitted patients, receiving experimental antiviral treatments, the interaction between some of those and NOACs may result in very high plasma levels of the latter. There is so far almost no clinical evidence supporting prophylaxis with therapeutic doses of heparin, and the possibility of increased risk of bleeding has to be taken into account. Some guidance or position documents render support for VTE prophylaxis in patients who are treated at home and for postdischarge prophylaxis in the case of additional risk factors for VTE, such as obesity, old age, reduced mobility, previous VTE, or active cancer. For these patients, NOACs have advantages over VKA and LMWH.

Treatment of VTE should follow generally accepted principles. Since the risk of VTE seems to increase with the severity of COVID-19, many of the patients diagnosed with VTE will have or be at risk for multiorgan failure. Parenteral anticoagulation is therefore preferred for those patients. Adjustments of the UFH dose can be problematic with aPTT due to unpredictable test results in severely ill patients. The role of fibrinolytic agents, particularly in nebulized form, deserves to be investigated further for possible benefit 
against pulmonary microthrombosis or PE. A multidisciplinary $\mathrm{PE}$ response team can be very beneficial also during the COVID-19 pandemic to assist with difficult treatment decisions.

\section{Conflict of Interest}

S.S. reports grants from Boehringer-Ingelheim and Octapharma, personal fees from Boehringer-Ingelheim, Bayer, Daiichi, Alnylam, Sanofi, Bristol-Myers Squibb, and Pfizer, outside the submitted work. S.K. reports research grants from Bayer AG, Boehringer-Ingelheim, and Actelion Janssen; educational grants from Biocompatibles Group UKBoston Scientific and Daiichi Sankyo; lecture fees from Bayer AG, Pfizer-Bristol-Myers Squibb, and MSD, all outside the submitted work. Y.H. has nothing to disclose.

\section{References}

1 Al-Ani F, Chehade S, Lazo-Langner A. Thrombosis risk associated with COVID-19 infection. A scoping review. Thromb Res 2020; 192:152-160

2 Huang C, Wang Y, Li X, et al. Clinical features of patients infected with 2019 novel coronavirus in Wuhan, China. Lancet 2020;395 (10223):497-506

3 Chen N,Zhou M, Dong X, et al. Epidemiological and clinical characteristics of 99 cases of 2019 novel coronavirus pneumonia in Wuhan, China: a descriptive study. Lancet 2020;395(10223):507-513

4 Danzi GB, Loffi M, Galeazzi G, Gherbesi E. Acute pulmonary embolism and COVID-19 pneumonia: a random association? Eur Heart J 2020;41(19):1858

5 Minet C, Potton L, Bonadona A, et al. Venous thromboembolism in the ICU: main characteristics, diagnosis and thromboprophylaxis. Crit Care 2015;19:287

6 Malato A, Dentali F, Siragusa S, et al. The impact of deep vein thrombosis in critically ill patients: a meta-analysis of major clinical outcomes. Blood Transfus 2015;13(04):559-568

7 Mehta P, McAuley DF, Brown M, Sanchez E, Tattersall RS, Manson JJHLH Across Speciality Collaboration, UK. COVID-19: consider cytokine storm syndromes and immunosuppression. Lancet 2020;395(10229):1033-1034

8 Qin C, Zhou L, Hu Z, et al. Dysregulation of immune response in patients with COVID-19 in Wuhan, China. Clin Infect Dis 2020;71 (15):762-768

9 Abou-Ismail MY, Diamond A, Kapoor S, Arafah Y, Nayak L. The hypercoagulable state in COVID-19: Incidence, pathophysiology, and management. Thromb Res 2020;194:101-115

10 Levi M, van der Poll T, Büller HR. Bidirectional relation between inflammation and coagulation. Circulation 2004;109(22): 2698-2704

11 Ranucci M, Ballotta A, Di Dedda U, et al. The procoagulant pattern of patients with COVID-19 acute respiratory distress syndrome. J Thromb Haemost 2020;18(07):1747-1751

12 Magro C, Mulvey JJ, Berlin D, et al. Complement associated microvascular injury and thrombosis in the pathogenesis of severe COVID-19 infection: A report of five cases. Transl Res 2020; 220:1-13

13 GaoT, Hu M, Zhang X, et al. Highly pathogenic coronavirus N protein aggravates lung injury by MASP-2-mediated complement overactivation. MedRxiv 2020. Doi: 10.1101/2020.03.29.20041962

14 Leisman DE, Deutschman CS, Legrand M. Facing COVID-19 in the ICU: vascular dysfunction, thrombosis, and dysregulated inflammation. Intensive Care Med 2020;46(06):1105-1108

15 Zhang Y, Xiao M, Zhang S, et al. Coagulopathy and antiphospholipid antibodies in patients with Covid-19. N Engl J Med 2020;382 (17):e38
$16 \mathrm{Xu}$ XW, Wu XX, Jiang XG, et al. Clinical findings in a group of patients infected with the 2019 novel coronavirus (SARS-Cov-2) outside of Wuhan, China: retrospective case series. BMJ 2020; 368:m606

17 Duan Q Gong Z, Song H, et al. Symptomatic venous thromboembolism is a disease related to infection and immune dysfunction. Int J Med Sci 2012;9(06):453-461

18 Miesbach W, Makris M. COVID-19: coagulopathy, risk of thrombosis, and the rationale for anticoagulation. Clin Appl Thromb Hemost 2020;26:1076029620938149

19 Zhai Z, Li C, Chen Y, et al; Prevention Treatment of VTE Associated with COVID-19 Infection Consensus Statement Group. Prevention and treatment of venous thromboembolism associated with coronavirus disease 2019 infection: a consensus statement before guidelines. Thromb Haemost 2020;120(06):937-948

20 Frydman GH, Boyer EW, Nazarian RM, Van Cott EM, Piazza G. Coagulation status and venous thromboembolism risk in African Americans: a potential risk factor in COVID-19. Clin Appl Thromb Hemost 2020;26:1076029620943671

21 Chen H, Guo J, Wang C, et al. Clinical characteristics and intrauterine vertical transmission potential of COVID-19 infection in nine pregnant women: a retrospective review of medical records. Lancet 2020;395(10226):809-815

22 Poggiali E, Bastoni D, Ioannilli E, Vercelli A, Magnacavallo A. Deep vein thrombosis and pulmonary embolism: two complications of COVID19 pneumonia? Eur J Case Rep Intern Med 2020;7(05):001646

23 Vaughan CJ, Cronin H, Ryan PM, Caplice NM. Obesity and COVID19: a Virchow's triad for the 21st century. Thromb Haemost 2020. Doi: $10.1055 / \mathrm{s}-0040-1714216$

24 Helms J, Tacquard C, Severac F, et al; CRICS TRIGGERSEP Group (Clinical Research in Intensive Care and Sepsis Trial Group for Global Evaluation and Research in Sepsis). High risk of thrombosis in patients with severe SARS-CoV-2 infection: a multicenter prospective cohort study. Intensive Care Med 2020;46(06):1089-1098

25 Terpos E, Ntanasis-Stathopoulos I, Elalamy I, et al. Hematological findings and complications of COVID-19. Am J Hematol 2020;95 (07):834-847

26 Tang N, Li D, Wang X, Sun Z. Abnormal coagulation parameters are associated with poor prognosis in patients with novel coronavirus pneumonia. J Thromb Haemost 2020;18(04):844-847

27 Zhang L, Feng X, Zhang D, et al. Deep vein thrombosis in hospitalized patients with COVID-19 in Wuhan, China: prevalence, risk factors, and outcome. Circulation 2020;142(02):114-128

28 Zerwes S, Hernandez Cancino F, Liebetrau D, et al. Increased risk of deep vein thrombosis in intensive care unit patients with CoViD19 infections?-Preliminary data [in German] Chirurg 2020;91 (07):588-594

29 Koch V, Biener M, Müller-Hennessen M, et al. Diagnostic performance of D-dimer in predicting venous thromboembolism and acute aortic dissection. Eur Heart J Acute Cardiovasc Care 2020. Doi: $10.1177 / 2048872620907322$

30 Cui S, Chen S, Li X, Liu S, Wang F. Prevalence of venous thromboembolism in patients with severe novel coronavirus pneumonia. J Thromb Haemost 2020;18(06):1421-1424

31 Demelo-Rodríguez P, Cervilla-Muñoz E, Ordieres-Ortega L, et al. Incidence of asymptomatic deep vein thrombosis in patients with COVID-19 pneumonia and elevated D-dimer levels. Thromb Res 2020;192:23-26

32 Jin S, Jin Y, Xu B, Hong J, Yang X. Prevalence and impact of coagulation dysfunction in COVID-19 in China: a meta-analysis. Thromb Haemost 2020. Doi: 10.1055/s-0040-1714369

33 Lagunas-Rangel FA. Neutrophil-to-lymphocyte ratio and lymphocyte-to-C-reactive protein ratio in patients with severe coronavirus disease 2019 (COVID-19): A meta-analysis. J Med Virol 2020. Doi: $10.1002 /$ jmv.25819

34 Middeldorp S, Coppens M, van Haaps TF, et al. Incidence of venous thromboembolism in hospitalized patients with COVID-19. J Thromb Haemost 2020;18(08):1995-2002 
35 Guan WJ, Ni ZY, Hu Y, et al; China Medical Treatment Expert Group for Covid-19. Clinical characteristics of coronavirus disease 2019 in China. N Engl J Med 2020;382(18):1708-1720

36 Taylor FB Jr, Toh CH, Hoots WK, Wada H, Levi M; Scientific Subcommittee on Disseminated Intravascular Coagulation (DIC) of the International Society on Thrombosis and Haemostasis (ISTH). Towards definition, clinical and laboratory criteria, and a scoring system for disseminated intravascular coagulation. Thromb Haemost 2001;86(05):1327-1330

37 Wang D, Hu B, Hu C, et al. Clinical characteristics of 138 hospitalized patients with 2019 novel coronavirus-infected pneumonia in Wuhan, China. JAMA 2020;323(11):1061-1069

38 Violi F, Pastori D, Cangemi R, Pignatelli P, Loffredo L. Hypercoagulation and antithrombotic treatment in coronavirus 2019: a new challenge. Thromb Haemost 2020;120(06):949-956

39 Chaudhary R, Kreutz RP, Bliden KP, Tantry US, Gurbel PA. Personalizing antithrombotic therapy in COVID-19: role of thromboelastography and thromboelastometry. Thromb Haemost 2020. Doi: 10.1055/s-0040-1714217

40 Spiezia L, Boscolo A, Poletto F, et al. COVID-19-related severe hypercoagulability in patients admitted to intensive care unit for acute respiratory failure. Thromb Haemost 2020;120(06): 998-1000

41 Boscolo A, Spiezia L, Correale C, et al. Different hypercoagulable profiles in patients with COVID-19 admitted to the internal medicine ward and the intensive care unit. Thromb Haemost 2020. Doi: $10.1055 / \mathrm{s}-0040-1714350$

42 Tang N, Bai H, Chen X, Gong J, Li D, Sun Z. Anticoagulant treatment is associated with decreased mortality in severe coronavirus disease 2019 patients with coagulopathy. J Thromb Haemost 2020;18(05):1094-1099

43 Klok FA, Kruip MJHA, van der Meer NJM, et al. Incidence of thrombotic complications in critically ill ICU patients with COVID-19. Thromb Res 2020;191:145-147

44 Llitjos JF, Leclerc M, Chochois C, et al. High incidence of venous thromboembolic events in anticoagulated severe COVID-19 patients. J Thromb Haemost 2020;18(07):1743-1746

45 Lodigiani C, Iapichino G, Carenzo L, et al; Humanitas COVID-19 Task Force. Venous and arterial thromboembolic complications in COVID-19 patients admitted to an academic hospital in Milan, Italy. Thromb Res 2020;191:9-14

46 Di Minno A, Ambrosino P, Calcaterra I, Di Minno MND. COVID-19 and venous thromboembolism: a meta-analysis of literature studies. Semin Thromb Hemost 2020. Doi: 10.1055/s-00401715456

47 Lax SF, Skok K, Zechner P, et al. Pulmonary arterial thrombosis in COVID-19 with fatal outcome: results from a prospective, singlecenter, clinicopathologic case series. Ann Intern Med 2020;173 (05):350-361

48 Wichmann D, Sperhake JP, Lütgehetmann M, et al. Autopsy findings and venous thromboembolism in patients with COVID19. Ann Intern Med 2020;173(04):268-277

49 Stals MAM, Grootenboers MJ, van Guldener C, et al. Higher incidence of thrombotic complications in hospitalized patients with SARS-COV-2 virus versus influenza virus infections [abstract]. Res Pract Thromb Haemost 2020;4(Suppl 1. Available at: https:// abstracts.isth.org/abstract/higher-incidence-of-thrombotic-complications-in-hospitalized-patients-with-sars-cov-2-virus-versusinfluenza-virus-infections/. Accessed September 22, 2020

50 Chopard P, Spirk D, Bounameaux H. Identifying acutely ill medical patients requiring thromboprophylaxis. J Thromb Haemost 2006; 4(04):915-916

51 Barbar S, Noventa F, Rossetto V, et al. A risk assessment model for the identification of hospitalized medical patients at risk for venous thromboembolism: the Padua Prediction Score. J Thromb Haemost 2010;8(11):2450-2457

52 Gibson CM, Spyropoulos AC, Cohen AT, et al. The IMPROVEDD VTE risk score: incorporation of D-dimer into the IMPROVE score to improve venous thromboembolism risk stratification. TH Open 2017;1(01):e56-e65

53 Rosenberg D, Eichorn A, Alarcon M, McCullagh L, McGinn T, Spyropoulos AC. External validation of the risk assessment model of the International Medical Prevention Registry on Venous Thromboembolism (IMPROVE) for medical patients in a tertiary health system. J Am Heart Assoc 2014;3(06):e001152

54 Blondon M, Spirk D, Kucher N, et al. Comparative performance of clinical risk assessment models for hospital-acquired venous thromboembolism in medical patients. Thromb Haemost 2018; 118(01):82-89

55 Testa S, Prandoni P, Paoletti O, et al. Direct oral anticoagulant plasma levels' striking increase in severe COVID-19 respiratory syndrome patients treated with antiviral agents: the Cremona experience. J Thromb Haemost 2020;18(06):1320-1323

56 Bikdeli B, Madhavan MV, Jimenez D, et al; Global COVID-19 Thrombosis Collaborative Group, Endorsed by the ISTH, NATF, ESVM, and the IUA, Supported by the ESC Working Group on Pulmonary Circulation and Right Ventricular Function. COVID-19 and thrombotic or thromboembolic disease: implications for prevention, antithrombotic therapy, and follow-up: JACC State-of-the-Art Review. J Am Coll Cardiol 2020;75(23): 2950-2973

57 Yin S, Huang M, Li D, Tang N. Difference of coagulation features between severe pneumonia induced by SARS-CoV2 and nonSARS-CoV2. J Thromb Thrombolysis 2020. Doi: 10.1007/ s11239-020-02105-8

58 Paranjpe I, Fuster V, Lala A, et al. Association of treatment dose anticoagulation with in-hospital survival among hospitalized patients with COVID-19. J Am Coll Cardiol 2020;76(01): 122-124

59 Tremblay D, van Gerwen M, Alsen M, et al. Impact of anticoagulation prior to COVID-19 infection: a propensity scorematched cohort study. Blood 2020;136(01):144-147

60 Klok FA, Kruip MJHA, van der Meer NJM, et al. Confirmation of the high cumulative incidence of thrombotic complications in critically ill ICU patients with COVID-19: An updated analysis. Thromb Res 2020;191:148-150

61 Pesavento R, Ceccato D, Pasquetto G, et al. The hazard of (sub) therapeutic doses of anticoagulants in non-critically ill patients with Covid-19: the Padua province experience.J Thromb Haemost 2020. Doi: $10.1111 /$ jth. 15022

62 Al-Samkari H, Gupta S, Karp Leaf R, et al. Thrombosis, bleeding, and the effect of anticoagulation on survival in critically ill patients with COVID-19 in the United States [abstract]. Res Pract Thromb Haemost 2020;4(Suppl 1. Available at: https:// abstracts.isth.org/abstract/thrombosis-bleeding-and-the-effectof-anticoagulation-on-survival-in-critically-ill-patientswith-covid-19-in-the-united-states/. Accessed September 22, 2020

63 Cattaneo M, Bertinato EM, Birocchi S, et al. Pulmonary embolism or pulmonary thrombosis in COVID-19? Is the recommendation to use high-dose heparin for thromboprophylaxis justified?. Thromb Haemost 2020;120(08):1230-1232

64 Thachil J, Tang N, Gando S, et al. ISTH interim guidance on recognition and management of coagulopathy in COVID-19. J Thromb Haemost 2020;18(05):1023-1026

65 Spyropoulos AC, Levy JH, Ageno W, et al; Subcommittee on Perioperative, Critical Care Thrombosis, Haemostasis of the Scientific, Standardization Committee of the International Society on Thrombosis and Haemostasis. Scientific and Standardization Committee communication: clinical guidance on the diagnosis, prevention, and treatment of venous thromboembolism in hospitalized patients with COVID-19. J Thromb Haemost 2020;18 (08):1859-1865

66 Khider L, Soudet S, Laneelle D, et al; French Society of Vascular Medicine (SFMV). Proposal of the French Society of Vascular Medicine for the prevention, diagnosis and treatment of venous 
thromboembolic disease in outpatients with COVID-19. J Med Vasc 2020;45(04):210-213

67 Marietta M, Ageno W, Artoni A, et al. COVID-19 and haemostasis: a position paper from Italian Society on Thrombosis and Haemostasis (SISET). Blood Transfus 2020;18(03):167-169

68 American Society of Hematology. COVID-19 and VTE/anticoagulation: frequently asked questions. 2020 [cited 2020 July 26]. Available at: https://www.hematology.org/covid-19/covid-19and-vte-anticoagulation. Accessed September 22, 2020

69 Llau JV, Ferrandis R, Sierra P, et al. SEDAR-SEMICYUC consensus recommendations on the management of haemostasis disorders in severely ill patients with COVID-19 infection. Rev Esp Anestesiol Reanim 2020;67(07):391-399

70 Barnes GD, Burnett A, Allen A, et al. Thromboembolism and anticoagulant therapy during the COVID-19 pandemic: interim clinical guidance from the anticoagulation forum. J Thromb Thrombolysis 2020;50(01):72-81

71 Vivas D, Roldan V, Esteve-Pastor MA, et al. Recommendations on antithrombotic treatment during the COVID-19 pandemic. Position statement of the Working Group on Cardiovascular Thrombosis of the Spanish Society of Cardiology. Rev Esp Cardiol 2020; 73(09):749-757

72 Casini A, Alberio L, Angelillo-Scherrer A, et al. Thromboprophylaxis and laboratory monitoring for in-hospital patients with COVID-19 - a Swiss consensus statement by the Working Party Hemostasis. Swiss Med Wkly 2020;150:w20247

73 Roberts LN, Whyte MB, Georgiou L, et al. Postdischarge venous thromboembolism following hospital admission with COVID-19. Blood 2020; 136(11):1347-1350

74 Konstantinides SV, Meyer G, Becattini C, et al; ESC Scientific Document Group. 2019 ESC Guidelines for the diagnosis and management of acute pulmonary embolism developed in collaboration with the European Respiratory Society (ERS). Eur Heart J 2020;41(04):543-603

75 Mazzolai L, Aboyans V, Ageno W, et al. Diagnosis and management of acute deep vein thrombosis: a joint consensus document from the European Society of Cardiology working groups of aorta and peripheral vascular diseases and pulmonary circulation and right ventricular function. Eur Heart J 2018;39(47):4208-4218

76 Kearon C, Akl EA, Ornelas J, et al. Antithrombotic therapy for VTE disease: CHEST guideline and expert panel report. Chest 2016; 149(02):315-352

77 Kirchhof P, Benussi S, Kotecha D, et al. 2016 ESC Guidelines for the management of atrial fibrillation developed in collaboration with EACTS. Europace 2016;18(11):1609-1678

78 Steffel J, Verhamme P, Potpara TS, et al; ESC Scientific Document Group. The 2018 European Heart Rhythm Association Practical Guide on the use of non-vitamin K antagonist oral anticoagulants in patients with atrial fibrillation. Eur Heart J 2018;39(16): 1330-1393
79 Poissy J, Goutay J, Caplan M, et al; Lille ICU Haemostasis COVID-19 Group. Pulmonary embolism in patients with COVID-19: awareness of an increased prevalence. Circulation 2020;142(02): 184-186

80 Fauvel C, Weizman O, Trimaille A, et al; Critical Covid-19 France Investigators. Pulmonary embolism in COVID-19 patients: a French multicentre cohort study. Eur Heart J 2020;41(32): 3058-3068

81 Connors JM, Levy JH. COVID-19 and its implications for thrombosis and anticoagulation. Blood 2020;135(23):2033-2040

82 Bikdeli B, Madhavan MV, Gupta A, et al; Global COVID-19 Thrombosis Collaborative Group. Pharmacological agents targeting thromboinflammation in COVID-19: review and implications for future research. Thromb Haemost 2020;120 (07):1004-1024

83 Xiao M, Zhang Y, Zhang S, et al. Brief report: anti-phospholipid antibodies in critically ill patients with coronavirus disease 2019 (COVID-19). Arthritis Rheumatol 2020. Doi: 10.1002/art.41425

84 Pineton de Chambrun M, Frere C, Miyara M, et al. High frequency of antiphospholipid antibodies in critically-ill COVID-19 patients: a link with hypercoagulability? J Intern Med 2020. Doi: 10.1111/ joim. 13126

85 Abdel-Wahab N, Talathi S, Lopez-Olivo MA, Suarez-Almazor ME. Risk of developing antiphospholipid antibodies following viral infection: a systematic review and meta-analysis. Lupus 2018;27 (04):572-583

86 Pengo V, Denas G, Zoppellaro G, et al. Rivaroxaban vs warfarin in high-risk patients with antiphospholipid syndrome. Blood 2018; 132(13):1365-1371

87 Bauersachs R, Langer F, Kalka C, et al. Treatment of the antiphospholipid syndrome with direct oral anticoagulantsPosition statement of German societies. Vasa 2019;48(06):483-486

88 Whyte CS, Morrow GB, Mitchell JL, Chowdary P, Mutch NJ. Fibrinolytic abnormalities in acute respiratory distress syndrome (ARDS) and versatility of thrombolytic drugs to treat COVID-19. J Thromb Haemost 2020;18(07):1548-1555

89 Konstantinides SV, Vicaut E, Danays T, et al. Impact of thrombolytic therapy on the long-term outcome of intermediate-risk pulmonary embolism. J Am Coll Cardiol 2017;69(12):1536-1544

90 ESC. ESC guidance for the diagnosis and management of CV disease during the COVID-19 pandemic. 2020. Available at: https://www.escardio.org/Education/COVID-19-and-Cardiology/ ESC-COVID-19-Guidance. Accessed September 22, 2020

91 Meyer G, Vicaut E, Danays T, et al; PEITHO Investigators. Fibrinolysis for patients with intermediate-risk pulmonary embolism. $\mathrm{N}$ Engl J Med 2014;370(15):1402-1411

92 Zondag W, Mos IC, Creemers-Schild D, et al; Hestia Study Investigators. Outpatient treatment in patients with acute pulmonary embolism: the Hestia Study. J Thromb Haemost 2011;9(08): 1500-1507 